\title{
Nonlinear Response of Medium Size Continuous Bridges with LRB
}

[Bertha Olmos and José Manuel Jara]

\begin{abstract}
The main objectives of this work were to investigate the effects of the nonlinear behavior of the isolation pads on the seismic response of bridges with rubber bearings, and to identify when base isolation improved their seismic performance. To achieve these objectives a parametric study was conducted designing a set of bridges for three different soil types and varying the number of spans, span lengths, and pier heights. The seismic responses (accelerations, displacements and pier seismic forces) were evaluated for three different structural models. The first represented bridges without base isolation; the second corresponded to the same bridges including now rubber bearings with linear elastic behavior that shifted the natural period of the bridge by a factor of 2 to 4 . In the third model the seismic response of the base isolated bridges was studied accounting for the nonlinear behavior of the pads. The results show clearly the importance of the nonlinear behavior on the seismic performance of the bridges.
\end{abstract}

Keywords - LRB, Brisges, Time history analyses, Nonlinear seismic response, Bridges on hard soil, Bridges on medium stiffness soils.

\section{Introduction}

The idea of incorporating energy dissipation devices into structures is not new, and these devices have been implemented in many countries around the world, especially in structures that may be subjected to the action of accidental dynamic loads such as earthquakes. The implementation of this approach in underdeveloped countries is lagging because they may not have available all the technology needed for the design, nor the appropriate construction equipment. There are at present, many different types of energy dissipation devices that can be used to improve the performance of a structure; they are known under the generic name of structural control. The energy dissipation devices used for structural control can be passive, active, or semi-active (hybrid). In the case of existing bridges, base isolation is the easiest control system to incorporate since rubber bearings are already required at each support by the design codes; the rubber bearings can be easily replaced using jacks supported directly on the piers and abutments. For this reason, in this work base isolation was selected as the control system to be investigated. Base isolation bearings consist of alternated layers of rubber and steel, and can also include an inner lead core in order to increase the energy dissipation capacity of the unit; usually their shape is circular or square. Several constitutive models have been proposed in the literature to represent the nonlinear behavior of these control systems [2, 3], based on their hysteretic characteristics.
Bridges play an important role in the infrastructure and development of any country and their operability after a major disaster, such as an earthquake, is essential. It is desirable therefore to incorporate control systems that would decrease the seismic forces on important bridges that can be subjected to ground motions. That is the case of Mexico where several bridges were damaged during the most recent severe earthquake (Manzanillo, 1995). In this work we started designing according to the code provisions used in Mexico [4, 5] a set of 8 continuous bridges (with different span lengths and pier heights) for two types of soils (hard soil and medium soil). Isolation devices were then incorporated to assess the effects of these systems on the bridges' seismic response for two soil types [6, 7, and 8], leading to a total of 16 structures. This was considered important because most of the work related to lead-rubber bearings had considered until now structures located on hard soil. The selection of only two soil types (leaving out the soils type III), obeys to the general knowledge of the unfeasible applicability of the isolation systems in this type of soils. The dynamic characteristics of soft soils (large periods) and the possibility of having differential ground displacements during the service life of the structure make unsuitable the use of an isolation system in soft soils.

With the aim to study the effects of lead-rubber bearings (LRB) implemented in new designs or retrofitting, it was estimated the seismic response of the linear (bridges without base isolation, NI) and nonlinear (bridges with base isolation, WI) dynamic responses of the bridges subjected to 21 ground motions recorded on the Pacific Coast of Mexico. The responses of interest were the displacements on top of the piers, the pier angular distortions, the pier shear force and bending moment ratios, and the lead-rubber bearings' ductility demands for two seismic scenarios that are usually considered on the seismic design codes.

\section{Bridges Numerical Model}

The bridges considered were typical reinforced concrete (RC) bridges in Mexico, with 5 spans, each with lengths of 20 and $40 \mathrm{~m}$, and pier heights of 10 and $30 \mathrm{~m}$ (Figure 1) located on seismic zone D [4],potentially more dangerous for structures located in Mexico. The combination of the geometric parameters led to 4 different bridges that were designed for two soil types: hard soil (type I) and medium soil (type II), leading to 8 total cases. The design response spectra for seismic zone D considering a ductility factor of 2 and an importance factor of 1.5, as proposed in the code [4], were used for the design. The seismic response parameters 
considered the relative displacements and the absolute accelerations of the deck, the relative displacements and seismic forces in the piers, and the ductility demands for the isolation pads. The seismic responses were obtained for 21 ground motions. In the text each bridge is identified with a number and a letter referring to the number of spans, the span lengths, and the pier height. For example, the bridge referred to as $5 \mathrm{~S} 40 \mathrm{~L} 30 \mathrm{H}$ represents a 5-span bridge with $40 \mathrm{~m}$ spans and $30 \mathrm{~m}$ pier height. All the bridges were considered to be RC. All of the bridges had RC circular piers, RC slabs and RC bent caps. The diaphragms used in each of the bridges were RC. The modulus of elasticity, shear modulus and Poisson ratio were 2.5E10 $\mathrm{Pa}, 1.03 \mathrm{E} 10 \mathrm{~Pa}$ and 0.2 for the concrete, and 2E11 Pa, 7.7E10 Pa and 0.3 for the reinforcing steel. Figure 2 shows a schematic elevation of the 5 -span bridges.

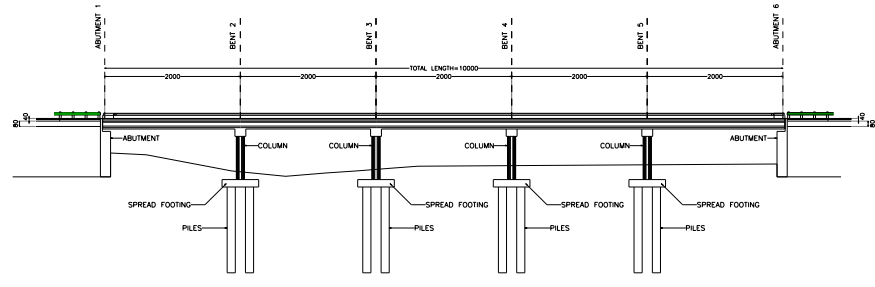

Figure 1. Bridges elevation view

In this work, the bridges were modelled as 3D structures and the analyses were carried out with the nonlinear SAP200 program. The first case of study was a representative model for the original bridges without lead-rubber bearings (NI). This model represents continuous existing bridges that are considered to be vulnerable under the action of seismic events and it is of interest to study their seismic response under extreme demands. The members (girders, diaphragms, bent caps, and piers) were modelled as beam elements where there was a continuous connection between girders and piers. The RC slab was modeled with a mesh of rectangular thin shell (plate bending and stretching) finite elements. The beams were supported at their ends by linear laminated rubber bearings. The bearings had an area of $0.09 \mathrm{~m}^{2}$, and a shear modulus of $981 \mathrm{kPa}$; the right and the left bearings had heights of 57 and $41 \mathrm{~mm}$, leading to stiffness values of 1962 and $2759 \mathrm{kN} / \mathrm{m}$ at each support, respectively. The base supports of the piers were considered fixed, neglecting the flexibility of their foundations. The beam elements used to model the girders were divided into small discrete segments with the mass distributed equally to each node, and the same amount of mass acting in the longitudinal and transverse directions. The behaviour of all bridges' components was considered linear. To seek the validity of this assumption the piers' angular distortions were evaluated. The abutments in bridges are usually very stiff elements with movement restrictions imposed by the surrounding ground. Therefore, bridges are usually considered simply supported on their ends and this assumption was adopted in this work.

The 3D models used for the isolated models (WI) incorporate lead-rubber hysteretic bearings modelled with link elements according to the Wen plasticity properties [3]. The WI models were the same described in the first case (NI) but with the inclusion of energy dissipation devices in the core of the bearings, and assuming that girders are continuous along the piers. The lead-rubber bearings had the same properties in the longitudinal and transverse directions, and were located at each of the beam supports. The nonlinear rubber bearings' properties were computed to produce a shift in the longitudinal natural period of the bridges by a factor of two to four without exceeding an allowable deformation [6, 7, and 9]. The analysis assumed that the energy dissipation devices were the only elements behaving nonlinearly and that the remaining elements had linear behavior. This hypothesis was validated through the analysis of the pier angular distortion, discussed on the results that showed values that do not represent excessive damage, even for the failure limit state.

The dynamic characteristics of the bridges were obtained from modal analyses. The natural periods for the NI bridges (TNI), and for the WI bridges (TWI) in the longitudinal and transverse directions are listed in Table 1 . The natural periods for each bridge are presented in two rows where the first one corresponds to translation in the longitudinal direction and the second to the transverse direction. The actual stiffness and period would vary in time increasing as the lead-rubber bearings behave nonlinearly. In the majority of the cases the lower, 1st and 2nd, mode shapes of the NI bridges corresponded to torsion and translation in the transverse direction whereas the isolated bridges had their first and second mode shapes a translation in the longitudinal and transverse directions, respectively. The number of spans does not show important influence on the bridges' natural periods.

TABLE I. NATURAL PERIODS IN THE LONGITUDINAL AND TRANSVERSE DIRECTIONS, RESPECTIVELY FIRST AND SECOND ROWS

\begin{tabular}{|c|c|c|c|c|c|c|c|c|c|}
\hline \multirow{2}{*}{ Bridge } & \multicolumn{2}{|c|}{ Soil type I } & \multicolumn{2}{|c|}{ Soil type II } & \multirow{2}{*}{ Bridge } & \multicolumn{2}{|c|}{ Soil type I } & \multicolumn{2}{|c|}{ Soil type II } \\
\hline & $\begin{array}{c}\mathrm{T}_{\mathrm{NI}} \\
(\mathrm{Sec})\end{array}$ & $\begin{array}{c}\mathrm{T}_{\mathrm{WI}} \\
(\mathrm{Sec})\end{array}$ & $\begin{array}{c}\mathrm{T}_{\mathrm{NI}} \\
(\mathrm{Sec})\end{array}$ & $\begin{array}{c}\mathrm{T}_{\mathrm{WI}} \\
(\mathrm{Sec})\end{array}$ & & $\begin{array}{c}\mathrm{T}_{\mathrm{NI}} \\
(\mathrm{Sec})\end{array}$ & $\begin{array}{l}\mathrm{T}_{\mathrm{WI}} \\
(\mathrm{Sec})\end{array}$ & $\begin{array}{c}\mathrm{T}_{\mathrm{NI}} \\
(\mathrm{Sec})\end{array}$ & $\begin{array}{c}\mathrm{T}_{\mathrm{WI}} \\
(\mathrm{Sec})\end{array}$ \\
\hline \multirow{2}{*}{ 5S20L10H } & 0.77 & 2.13 & 0.41 & 1.53 & \multirow{2}{*}{$5 \mathrm{~S} 20 \mathrm{~L} 30 \mathrm{H}$} & 1.72 & 5.06 & 1.38 & 2.98 \\
\hline & 0.65 & 1.52 & 0.52 & 1.22 & & 2.21 & 2.57 & 1.37 & 1.75 \\
\hline \multirow{2}{*}{ 5S40L10H } & 0.76 & 2.43 & 0.52 & 1.82 & \multirow{2}{*}{$5 \mathrm{~S} 40 \mathrm{~L} 30 \mathrm{H}$} & 2.03 & 4.54 & 1.72 & 3.18 \\
\hline & 0.76 & 2.33 & 0.33 & 1.44 & & 2.10 & 2.77 & 1.36 & 1.94 \\
\hline
\end{tabular}

Bertha Olmos and José Manuel Jara Civil Engineering Department / UMSNH Mexico 


\section{Seismic Demand}

Figure 2 shows the epicenters of the earthquakes considered in this work recorded on soils types I (a) y II (b). Twenty- one earthquakes with magnitude larger than 7.8 , were considered to studied the bridges' seismic responses. Ten of the records correspond to T-I and the others to T-II. In order to study the seismic behaviour of the bridges the records were scaled to the maximum acceleration expected for return periods of 50, service limit state, and 1000 years, failure limit state. The response spectra for the original records are shown in Figure 3.
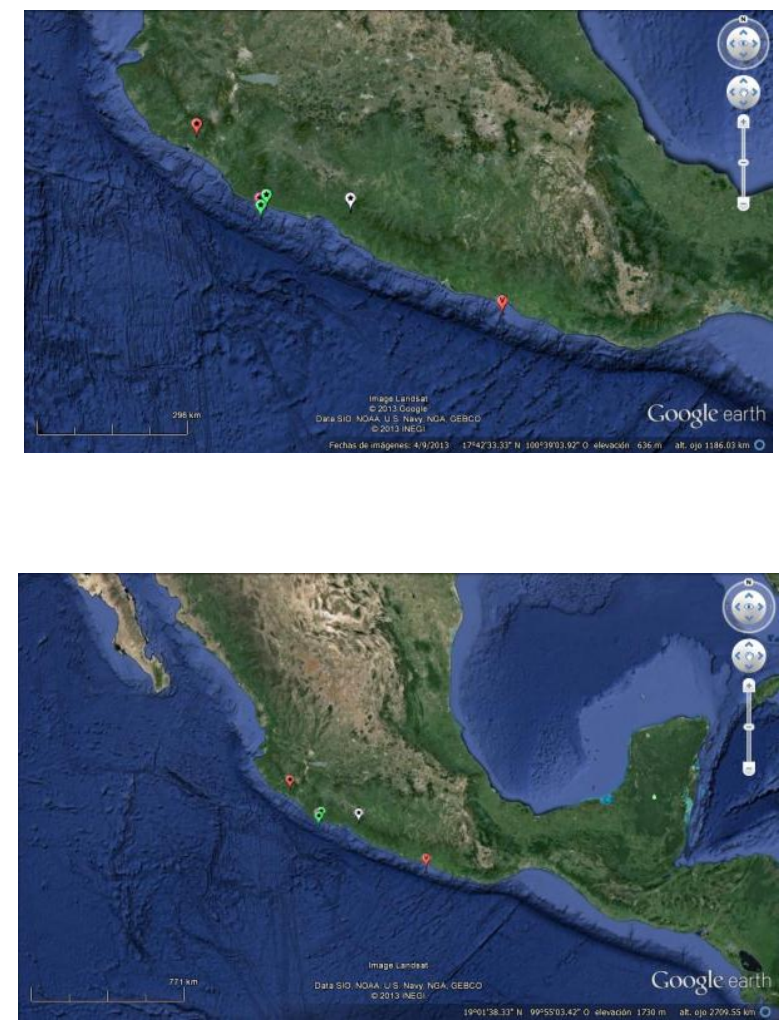

Figure 2. Epicenters' location for the earthquakes considered (a) Soil type I and (b) Soil type II
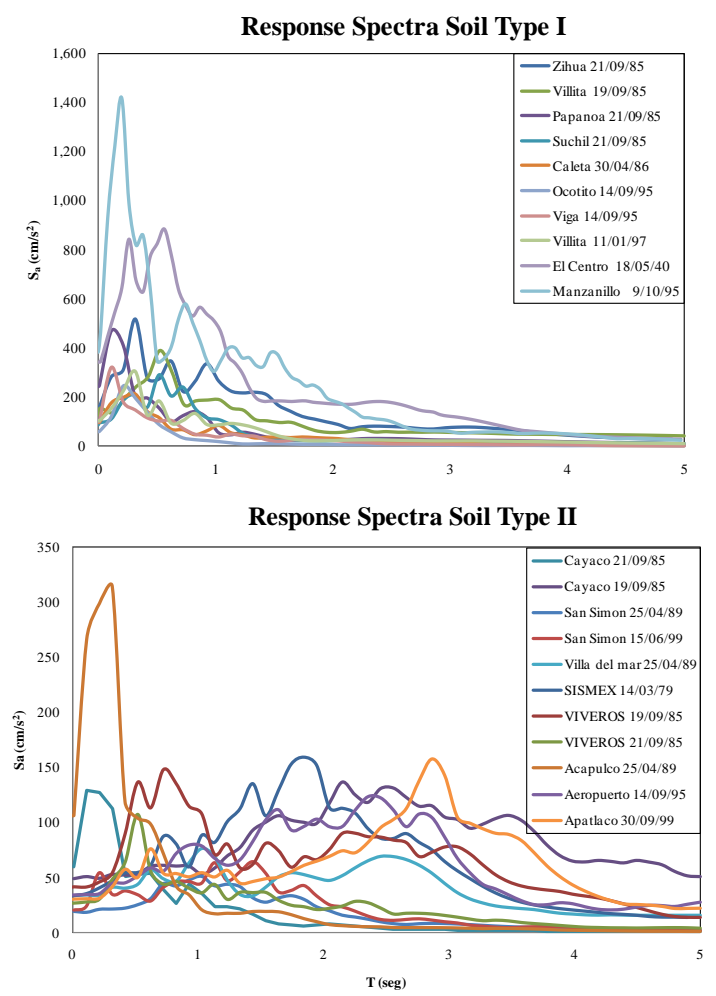

Figure 3. Seudoacceleration response spectra for soils types I and II

\section{Bridges' dynamic seismic response}

The beneficial or detrimental effects of the lead-rubber bearings on the bridges' seismic responses depend on the natural period of the bridge, the damping due to the nonlinear behaviour, and the type of excitation. As it would be expected from the shape of the response spectra that there could be important reductions in the acceleration and shear forces due to the period shift caused by the base isolation. On the other hand, there would be increases or decreases on the relative displacements of the deck depending not only on the natural periods but also on the energy dissipation and the ground motion characteristics. If the ground input energy lies in the zone of short periods, it is expected that the seismic responses would be reduced when the structural period shifted out of this range; that is true for bridges built on hard soil sites whereas this is not true for the ones located on medium soil, as can be seen in figure 3 . The additional damping caused by the nonlinear behaviour of the LRB should play a key role in this case.

A discussion on the bridges' seismic response is presented in this section based on the central piers' demands. The validity of this assumption is based on the geometric symmetry of the bridges about two orthogonal axes. The analyses of the results for bridges with and without isolation are based on the maximum shear and maximum flexure 
demands on the piers, the maximum relative displacements at the top of the piers, the maximum relative displacements, the absolute accelerations at the deck level, and the isolator maximum ductility demands. The nonlinear responses were estimated through nonlinear time history analyses by direct integration of the dynamic equilibrium equations with the Newmark method. To estimate the dynamic response was considered a damping ratio of $5 \%$ for the two first natural periods of the bridges defined in the program as Rayleigh damping. The amount of damping developed by the isolators is automatically defined from their nonlinear hysteretic behaviour. The analyses were led considering the earthquakes acting in two orthogonal directions, named longitudinal and transverse that correspond to the longitudinal and transverse directions of the bridges.

Figure 4 and 5 show the maximum ratios of the forces demanded on the piers, shears and bending moments, for all the bridges in study, the two types of soils and the two seismic scenarios (return periods of 50 and 1000 years), respectively for the longitudinal and transverse directions. The ratios are defined as the maximum shear demanded by the isolated bridges to the maximum shear demanded by the non-isolated one, in a similar way is defined the bending moment ratio. In the figures the abscissa represent the bridges and the ordinate corresponds to the shear or bending moment ratios; the demands for bridges located on soil types I and II are represented with white and gray bars, respectively; the figures' rows correspond to the shear ratios whereas the columns correspond to the demand scenarios of 50 and 1000 years, respectively first and second columns. The results show that for all the cases considered the ratios are lower than one, it means that the inclusion of an isolation system reduces de shear forces and bending moments demanded on the piers under earthquakes of medium and high intensity, the reductions are in an interval of 50 to $85 \%$ and 50 to $85 \%$ for the shear ratio in the longitudinal and transverse directions, respectively, whereas for the bending moment ratio the intervals correspond to 15 to $80 \%$ and to 50 to $85 \%$ respectively for the longitudinal and transverse directions. The larger reductions on these demands correspond to the bridges with the shortest piles $(\mathrm{H}=10 \mathrm{~m})$. The isolation systems show to be very effective in reducing the forces and moments on the piers for both types of soil and for the two seismic scenarios considered ( $\mathrm{Tr}=50$ and 1000 years).
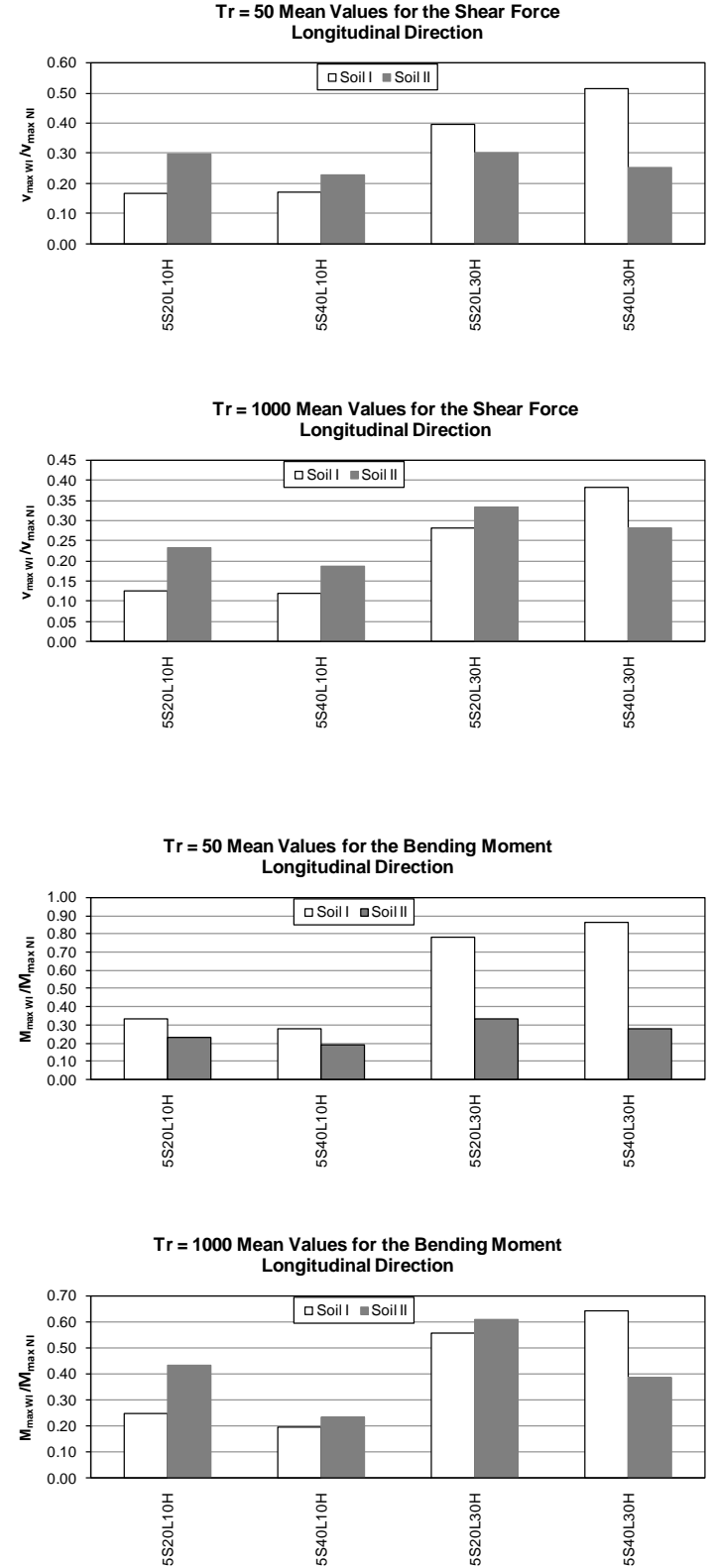

Figure 4. Central piles' shear and flexural moments when considering the earthquakes acting in the longitudinal direction for soils types I and II 
Proc. of the Seventh Intl. Conf. on Advances in Civil, Structural and Mechanical Engineering - CSM 2018 Copyright ( Institute of Research Engineers and Doctors, USA .All rights reserved.

ISBN: 978-1-63248-163-4 DOI: 10.15224/978-1-63248-163-4-17
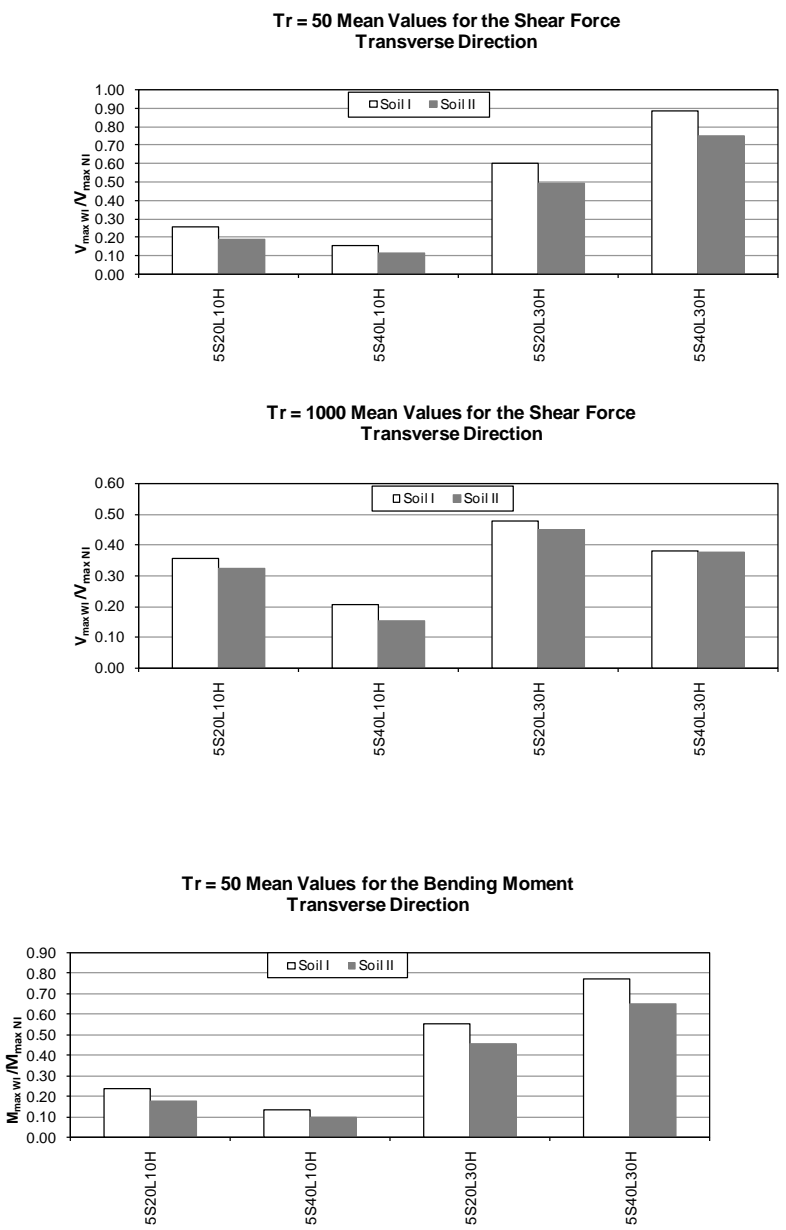

$\mathrm{Tr}=1000$ Mean Values for the Bending Moment Transverse Direction

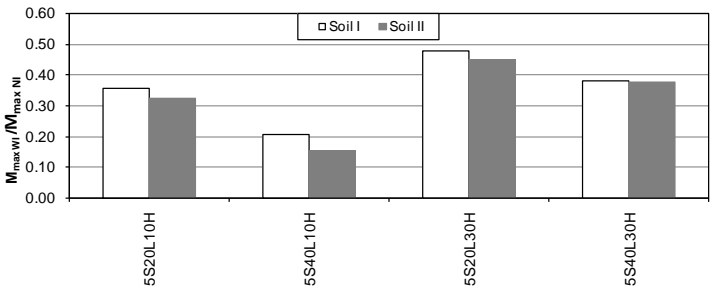

Figure 5. Central piles' shear and flexural moments when considering the earthquakes acting in the transverse direction for soils types I and II

The maximum values for the displacements on top of the piers and deck, the pier angular distortions, and the leadrubber bearings' ductility demands for two seismic scenarios that are usually considered on the seismic design codes are reported on tables 2 and 3 for the longitudinal direction, and 4 and 5 for the transverse direction. The responses reported on each row of the tables correspond to each of the bridges in study.

With respect to the bridges dynamic behaviour in the longitudinal direction (Tables 2 and 3), it is noticeable that when isolation is included the displacements on top of the piles reduced on the average of $50 \%$ for the bridges with piers height of $10 \mathrm{~m}$ whereas for bridges with slender piers $(\mathrm{H}=30$ $\mathrm{m}$ ) the displacements increased up to $50 \%$ for soil type I whereas for soil type II the increases are up to $4 \%$, showing the isolation effectiveness on medium stiffness soils. The pier angular distortions for a seismic demand corresponding to the service limit state ( $\mathrm{Tr}=50$ years) show values lower equal to 0.006 for the non-isolated bridges that correspond to negligible or light damage states; when including the isolation systems, the piers' angular distortions decreased in all cases to values that do not generate damage on them [10]. For a seismic scenario equivalent to the failure limit state, the piers distortion demands show that bridges without an isolation systems could achieve from moderate to severe damage states, states that could be classified as light when accounting for an isolation device [10]. These results show the isolation effectiveness in preventing severe damage on the piers, considered as the most vulnerable element for a bridge system. With respect to the accelerations demands on top of the piers and deck, for all the cases the reductions are considerable with the exception of the bridge 5S40L10H located on soil type I that present increases in this parameter. In the case of the lead rubber bearings, we can see that the ductility demands correspond to almost elastic behaviour for the service limit state and soil type I whereas for soil type II and all cases under the failure limit state show an important LRB nonlinear behaviour achieving ductility values up to 33. These results are most significant for the medium stiffness soil type considered since it means important reductions on the bridges' seismic demands, leading to a justification to use the isolation systems in bridges located on soil type II. However, as shown in table 4, the isolator ductility demands in transverse direction can be a limitation for the traditional manufactured devices.

TABLE II. BRIDGES SEISMIC RESPONSE FOR EARTHQUAKE ACTING IN THEIR LONGITUDINAL DIRECTION FOR A RETURN PERIOD OF 50 YEARS

\begin{tabular}{|c|c|c|c|c|c|c|c|c|c|}
\hline \multirow{3}{*}{ Bridge } & \multicolumn{3}{|c|}{$\mathrm{U}_{\max }(\mathrm{cm})$} & \multirow{2}{*}{\multicolumn{2}{|c|}{$\begin{array}{c}\phi(\mathrm{rad}) \\
\text { Pier top }\end{array}$}} & \multicolumn{3}{|c|}{$A_{\max }\left(m / s^{2}\right)$} & \multirow{3}{*}{$\begin{array}{c}\mu \\
\text { LRB } \\
\text { WI }\end{array}$} \\
\hline & \multicolumn{2}{|c|}{ Pier top } & \multirow{2}{*}{$\begin{array}{c}\text { Deck } \\
\text { WI }\end{array}$} & & & \multicolumn{2}{|c|}{ Pier top } & \multirow{2}{*}{$\begin{array}{c}\text { Deck } \\
\text { WI } \\
\end{array}$} & \\
\hline & NI & WI & & NI & WI & NI & WI & & \\
\hline 5S20L10H & 2.269 & 1.448 & 5.191 & 0.002 & 0.001 & 2.149 & 1.637 & 0.334 & 1.64 \\
\hline $5 \mathrm{~S} 40 \mathrm{~L} 10 \mathrm{H}$ & 2.174 & 0.883 & 6.954 & 0.002 & 0.001 & 1.555 & 1.796 & 0.233 & 1.58 \\
\hline $5 \mathrm{~S} 20 \mathrm{~L} 30 \mathrm{H}$ & 5.082 & 7.672 & 11.044 & 0.002 & 0.003 & 0.686 & 0.278 & 0.165 & 1.95 \\
\hline $5 \mathrm{~S} 40 \mathrm{~L} 30 \mathrm{H}$ & 5.541 & 7.205 & 10.710 & 0.002 & 0.002 & 0.537 & 0.326 & 0.182 & 2.37 \\
\hline \multicolumn{10}{|c|}{ Soil Type II \& Maximum Central Piles' Dynamic Responses in the Long. Direction } \\
\hline \multirow{3}{*}{ Bridge } & \multicolumn{3}{|c|}{$\mathrm{U}_{\max }(\mathrm{cm})$} & \multirow{2}{*}{\multicolumn{2}{|c|}{$\phi($ rad) }} & \multicolumn{3}{|c|}{$A_{\max }\left(m / s^{2}\right)$} & $\mu$ \\
\hline & \multicolumn{2}{|c|}{ Pier top } & Deck & & & \multicolumn{2}{|c|}{ Pier top } & Deck & LRB \\
\hline & NI & WI & WI & NI & WI & NI & WI & WI & WI \\
\hline 5S20L10H & 1.094 & 1.019 & 20.294 & 0.001 & 0.001 & 2.582 & 2.366 & 0.919 & 6.48 \\
\hline 5S40L10H & 1.245 & 0.400 & 22.211 & 0.001 & 0.000 & 2.353 & 2.031 & 0.602 & 8.77 \\
\hline $5 \mathrm{~S} 20 \mathrm{~L} 30 \mathrm{H}$ & 9.969 & 9.441 & 28.058 & 0.003 & 0.003 & 2.167 & 1.588 & 0.618 & 8.95 \\
\hline $5 \mathrm{~S} 40 \mathrm{~L} 30 \mathrm{H}$ & 17.622 & 7.597 & 25.093 & 0.006 & 0.003 & 2.369 & 1.666 & 0.383 & 10.17 \\
\hline
\end{tabular}

TABLE III. BRIDGES SEISMIC RESPONSE FOR EARTHQUAKE ACTING IN THEIR LONGITUDINAL DIRECTION FOR A RETURN PERIOD OF 1000 YEARS

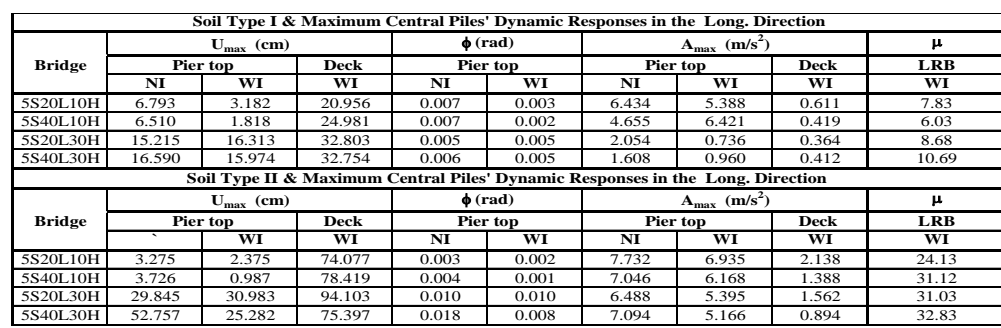


Proc. of the Seventh Intl. Conf. on Advances in Civil, Structural and Mechanical Engineering - CSM 2018

Copyright (C) Institute of Research Engineers and Doctors, USA .All rights reserved.

ISBN: 978-1-63248-163-4 DOI: 10.15224/978-1-63248-163-4-17

TABLE IV. BRIDGES SEISMIC RESPONSE FOR EARTHQUAKE ACTING IN THEIR TRANSVERSE DIRECTION FOR A RETURN PERIOD OF 50 YEARS

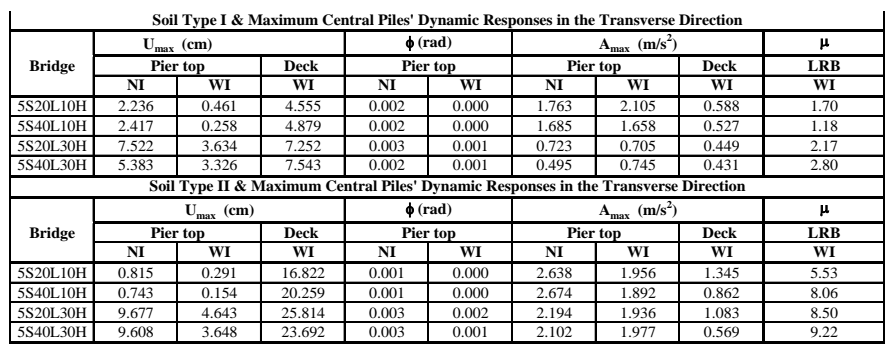

TABLE V. BRIDGES SEISMIC RESPONSE FOR EARTHQUAKE ACTING IN THEIR TRANSVERSE DIRECTION FOR A RETURN PERIOD OF 1000 YEARS

\begin{tabular}{|c|c|c|c|c|c|c|c|c|c|}
\hline \multirow{3}{*}{ Bridge } & \multicolumn{3}{|c|}{$\mathrm{U}_{\max }(\mathrm{cm})$} & \multicolumn{2}{|c|}{$\phi(\mathrm{rad})$} & \multicolumn{3}{|c|}{$A_{\max }\left(\mathrm{m} / \mathrm{s}^{2}\right)$} & \\
\hline & \multicolumn{2}{|c|}{ Pier top } & Deck & \multicolumn{2}{|c|}{ Pier top } & \multicolumn{2}{|c|}{ Pier top } & \multirow{2}{*}{$\begin{array}{c}\text { Deck } \\
\text { WI }\end{array}$} & \multirow{2}{*}{$\begin{array}{c}\mu \\
\text { LRB } \\
\text { WI }\end{array}$} \\
\hline & NI & WI & WI & $\mathrm{NI}$ & WI & NI & WI & & \\
\hline 5S20L10H & 6.695 & 1.018 & 16.830 & 0.007 & 0.001 & 5.277 & 6.426 & 0.984 & 6.59 \\
\hline $5 \mathrm{~S} 40 \mathrm{~L} 10 \mathrm{H}$ & 7.236 & 0.570 & 22.095 & 0.007 & 0.001 & 5.046 & 4.265 & 1.246 & 5.47 \\
\hline $5 \mathrm{~S} 20 \mathrm{~L} 30 \mathrm{H}$ & 22.522 & 8.950 & 25.680 & 0.008 & 0.003 & 2.164 & 2.170 & 0.827 & 9.75 \\
\hline $5 \mathrm{~S} 40 \mathrm{~L} 30 \mathrm{H}$ & 16.117 & 8.414 & 27.151 & 0.005 & 0.003 & 1.482 & 2.430 & 1.119 & 12.57 \\
\hline \multicolumn{10}{|c|}{ Soil Type II \& Maximum Central Piles' Dynamic Responses in the Transverse Direction } \\
\hline \multirow{3}{*}{ Bridge } & \multicolumn{3}{|c|}{$\mathrm{U}_{\max }(\mathrm{cm})$} & \multirow{2}{*}{\multicolumn{2}{|c|}{$\phi$ (rad) }} & \multicolumn{3}{|c|}{$\mathrm{A}_{\max }\left(\mathrm{m} / \mathrm{s}^{2}\right)$} & $\mu$ \\
\hline & \multirow{2}{*}{\multicolumn{2}{|c|}{\begin{tabular}{l}
\multicolumn{2}{c}{ Pier top } \\
NI
\end{tabular}}} & Deck & & & \multicolumn{2}{|c|}{ Pier top } & Deck & LRB \\
\hline & & & WI & \multicolumn{2}{|c|}{\begin{tabular}{c}
\multicolumn{2}{c}{ Pier top } \\
PI
\end{tabular}} & NI & WI & WI & WI \\
\hline 5S20L10H & 2.440 & 0.794 & 80.517 & 0.002 & 0.001 & 7.899 & 6.183 & 3.464 & 26.62 \\
\hline $5 \mathrm{~S} 40 \mathrm{~L} 10 \mathrm{H}$ & 2.224 & 0.346 & 73.615 & 0.002 & 0.000 & 8.006 & 5.674 & 1.980 & 29.35 \\
\hline $5 \mathrm{~S} 20 \mathrm{~L} 30 \mathrm{H}$ & 28.974 & 13.032 & 86.566 & 0.010 & 0.004 & 6.568 & 6.035 & 2.450 & 28.60 \\
\hline $5 \mathrm{~S} 40 \mathrm{~L} 30 \mathrm{H}$ & 28.765 & 10.886 & 89.422 & 0.010 & 0.004 & 6.293 & 6.384 & 1.460 & 35.76 \\
\hline
\end{tabular}

\section{v. Conclusions}

In this work, the nonlinear seismic response of medium size continuous bridges with and without LRB located on two soil types and two seismic scenarios has been studied. The discussion of the results showed the beneficial effects achieved on seismic demands when including the LRB that showed to prevent extensive damage on piers, but the inclusion of the isolation systems may be the cause of damage on the shear keys if there is not considered during the design processes the increases on the displacements demands for the transverse direction of the bridge. In general, the piers' shear force and bending moments decreased considerable when the isolation system is incorporated, in the same way the acceleration demands present important reductions for both of the seismic scenarios considered, service and failure limit states. It is generally accepted the beneficial effect of LRB systems to decrease the bridges' seismic responses on hard soil (soil type I). This study show that even for medium soil type (with not only high frequency content of high frequencies but also with important amplitudes on medium frequencies) the isolation systems can be an attractive alternative to reduce the seismic bridges' demands.

\section{Acknowledgment}

This study has been supported by the Mexican Ministry of Public Education (SEP) through the research program of the Universidad Michoacana de San Nicolás de Hidalgo.

\section{References}

[1] R.A. Imbsen, "Use of isolation for seismic retrofitting bridges," Journal of Bridge Engineering, vol. 6, No. 6, pp. 425-438, 2001.
[2] M.A. Hosam-Eddin and A.M. Abdel-Ghaffar, "Modellling of rubber and lead passive-control bearings for seismic anañysis," Journal of Structural Engineering, vol. 121, No. 7, pp. 1134-1144, 1995.

[3] Y. Wen, "Method for random vibrations of hysteretic systems," Journal of Mechanics Division, vol. 102, No. 2, pp. 249-263, 1976.

[4] CFE, Manual de Obras Civiles: Diseño pór sismo, Comisión Federal de Electricidad e Instituto de Investigaciones Eléctricas, Mexico, 1993.

[5] AASHTO, American Association of State Highway and Transportation Officials: Standard Specifications for Seismic Design of Highway Bridges, Washington, D.C., 1991.

[6] AASHTO, American Association of State Highway and Transportation Officials: Guide Specifications for Seismic Isolation Design, Washington, D.C., 2000.

[7] CALTRANS, Bridges Design Specifications, Department of Transportation, State of California, Sacramento, California, 1987.

[8] NZMWD, Design of lead-rubber bridge bearings, New Zeland Ministry of Works and Development, Civil Division Publication 818/A, Willington, New Zeland, 1983.

[9] J.N. Priestley, F. Seible and G.M. Calvi, Seismic Design and Retrofit of Birdges, John Wiley \& Sons, Inc., NY, 1996.

[10] R. Akbari, "Seismic fragility analysis of reinforced concrete continuous span bridges with irregular configutarion," Structure and Infrastructure Engineering, vol. 8, No. 9, pp. 425-438, 2012. 